\title{
EAST syndrome
}

INSERM

\section{Source}

INSERM. (1999). Orphanet: an online rare disease and orphan drug data base. EAST syndrome. ORPHA:199343

SeSAME syndrome is characterized by seizures, sensorineural deafness, ataxia, intellectual deficit, and electrolyte imbalance (hypokalemia, metabolic alkalosis, and hypomagnesemia). 